\title{
Editorial
}

\section{Higher Education and Labour Markets: Challenges for society}

Dear colleagues, HSM readers,

On behalf of the Editorial Board of Human Systems Management and as a guest editors of this issue, we are glad to introduce the thematic special issue "Higher Education and Labour Markets: Challenges for society".

Education and training in general are enabling all countries to become a knowledge-based society, particularly by improving employability. The need for appropriate training and skills has been underlined in the majority of world-wide employment policies, as in the future only those with appropriate knowledge and skills will flourish in the labour market.

It is still hard to grasp the scale and scope of COVID-19's global impact. A third of the world population was under some sort of "lockdown". Many economists argue that a second crisis, in the form of an economic recession, is underway. Countries took different measures to assure a minimum stability. For example, during the recession, EU members did not use fiscal policies to ease the recession, while the reinsurance system in the case of unemployment would achieve exactly this, as it acts as an automatic stabilizer. The response to unemployment in the great recession and subsequent events related to the European debt crisis has been very heterogeneous across Europe and in population groups.

This special thematic issue focuses on higher education with a particular emphasis on the labour market. Higher education institutions play a crucial role in providing high-level professional competences, giving graduates a base of knowledge and skills, but also enabling them to constantly adapt to changing labour conditions. For example, the development of the European Higher Education Area (EHEA) has been an important instrument in the EU integration process and employability has been one of its main goals from its very beginning. There are at least two important challenges facing universities within the EHEA in relation to labour market demand: (1) Providing education and training based on competences and skills that enable graduates to meet the needs of the labour market; (2) Active dialogue between higher education institutions and employers.

Authors and papers were invited from a range of fields, such us human resource management, higher education studies, labour market studies, or international studies. The received papers addressed topics as knowledge-driven competitiveness and entrepreneurial thinking, innovation for growth and jobs, Europe's competencies in an increasing competitive world, project management, the art and craft of publishing, European integration, education in the EU, management in higher education, globalization, internationalization, europeanisation through mobility and cooperation, HE and regional policies, quality assurance policies in HE, employment policies, soft skills in HE, ICT and on-line learning in HE and at the workplace, migration and multicultural societies, and human rights for education and work. Of course, the COVID-19 had great influence on research.

We selected to publish in this issue eight papers, being the first three labelled as "HSM revival" papers as, in our opinion, those papers address topics that could have an impact on the development of our journal, Human System Management.

"Does higher education properly prepare graduates for the growing artificial intelligence market? Gaps identification using text mining", authored by Benhayoyn and Lang, identifies the gaps in terms of skills between academic training on AI in French engineering and Business Schools, and the requirements of the labour market. Characterization of three classes of skills for the AI market: Technical, Soft and Interdisciplinary. Skills' gaps concern some profes- 
sional certifications and the mastery of specific tools, research abilities, and awareness of ethical and regulatory dimensions of AI. The article brings a deep analysis using algorithms for Natural Language Processing. Results provide a better understanding of the AI capability components at the individual and the organizational levels. This study that can help shape educational programs to respond to the AI market requirements.

"Virtual migration of higher education institutions in times of crisis: Major challenges and critical success factors", authored by Shatat and Shatat, presents Critical Success Factors (CSFs), which enabled many universities to transform efficiently into the virtual environment. Before this transition, universities should carefully consider the key challenges and the CSFs to achieve successful migration to the virtual environment. The results of the study indicate a positive and significant relationship notable impact of the 13 CSFs and the e-learning systems usage. The outcome of this research identifies the top $13 \mathrm{CSF}$ that contribute to delivering successful e-learning systems usage. The top 13 CSFs are positively and significantly correlated with e-learning systems usage.

"Ready for the future? Employability skills and competencies in the twenty-first century: The view of international experts", authored by Rakowska and Espinosa, aims to identify the twenty-first century's major employability skills and competencies, as well as the main demand trends for skills and competencies. The most valued employability skills were of a generic nature, in all three countries. Regarding specific skills, those of a social and managerial nature were the most highly valued. Work experience and formal education became less relevant for employability. The study's results can lead to recommendations on how to design a more employability-oriented curriculum in educational institutions.

"Quality of teaching in Kosovo's higher education institutions: Viewpoints of institutional leaders and lecturers", authored by Sokoli, Trunk Širca and Koren, studies the quality of teaching and identifies the characteristics and best practices on supporting, developing, and improving Kosovo's higher educational system's effectiveness by improving the quality of teaching. According to professors' opinions, the quality of teaching is related to the research of professors, and it depends on the experience of the teacher, knowledge transfer, technology use, and degree of professor qualification. Kosovo should establish appropriate mechanisms and policies for evaluating professors' performance and make their selection and re-election based on these performance indicators and not only based on formal documents.

"Do HR practices facilitate innovative work behaviour? Empirical evidence from higher education institutes", authored by Zreen, Farrukh and Kanwal, investigates the role of high-performance work practices (HPWP) in fostering innovative work behaviour (IWB) of service sector employees. Findings show that selection and training \& development play a significant role in fostering innovative work behaviour. Moreover, self-efficacy proved to be a significant mediator in the mechanism of HPWP-IWB. The finding of the study underpins the reciprocity perspective of the social exchange theory (SET). Additionally, the study also endorses that human resources are not something companies do, but they are what run businesses.

“Teachers' competencies for working in an intercultural environment", authored by Dermol, Klemenčič, Trunk and Çayır, discusses the teachers' competencies to work in an intercultural environment and presents the results from data collected within the RoMigSc project. These data are analysed to identify the competencies teachers need to work in a multicultural environment. The results show that teachers do not feel well prepared to support learning or teach human rights, emigration and immigration, shared values and discrimination. They also need more support in teaching in an intercultural and multicultural environment, especially out-of-school support. In general, teachers find their school and own practices inclusive for migrant and Roma students, but not in all aspects. None of the teachers has participated in a project to raise awareness of Roma issues.

"Quality of Human Capital Accumulation, Higher Education Graduates and Economic Growth: comparative analysis between BRICS and Southeast Asian countries and MENA countries", authored by Khalfaoui and Derbali, aims to investigate the impact of quality of human capital accumulation on economic growth for BRICS, Southeast Asian and MENA countries. The empirical results show that for BRICS and South East Asia countries, the nexus between quality of human capital and economic growth is positive, while for MENA countries the relationship has not been identified. The relationship between human capital and economic growth does 
not only depend on the employment rate of university graduates and labour market matching mechanisms, but also on the nature of the job and the efficiency and productivity of human capital.

"The impact of transformational leadership on organizational citizenship behaviour: Evidence from Malaysian higher education context", authored by Al-Mamary, examines the role of organizational commitment in mediating the relationship between transformational leadership and organizational citizenship behaviour (OCB). The findings of this study show that transformational leadership has significant direct effect on organizational commitment and organizational commitment has significant direct effect on OCB. These results highlight the importance of mediating role of organizational commitment in predicting transformational leadership-OCB relationship. The leaders in Malaysian research universities could utilize these findings by setting up strategies to promote transformational leadership and maximize the feeling of academic staff of being committed; this will enhance citizenship behaviour of academic staff.

We sincerely thank Prof. dr. Nada Trunk, the Editor in-Chief, who trusted us with this responsibility. We would like to thank all authors for their effort of preparing and revising the papers, and also a big "thank you" to all the reviewers who contributed to the quality of published papers. We look forward to working with you all in the future, as we continue to make HSM a success and we welcome your submissions.

Dr Aleš Trunk

International School for Social and Business

Studies, Slovenia

E-mail: ales.trunk@mfdps.si

Dr David Dawson

University of Gloucestershire, UK

E-mail: ddawson@glos.ac.uk

Guest editors 